\title{
Welcome from the Associate Vice-President
}

SURG acknowledges the excellence and the role of undergraduates in contributions across the campus to world-class research at the University of Guelph.

We take particular pride in the outstanding students at Guelph who choose to pursue graduate studies and careers, as a result of the experiential learning gained in a research setting at the University. SURG, a student-led initiative, will provide a new level of exposure to the research enterprise, and experiences which will further develop the communication and leadership skills of our students - a hallmark of a Guelph graduate.

Thanks to all of the students, staff, and faculty whose work led to the publication of this inaugural issue. In particular, I would like to commend SURG Editor Matt Teeter, the communications staff of the Office of Research, and McLaughlin Library for their work in creating SURG.

Sincerely,

Dr. Steven N. Liss

Associate Vice-President (Research Services)

$\&$ Professor, Department of Environmental Biology

\section{Welcome from the Editor of SURG}

Welcome to the inaugural issue of SURG. Though this journal strives to be at the forefront of many areas in publishing such as open access, no aspect is more important than highlighting the significant contributions undergraduates make to research.

In a short period of time, we have collected seven full-length articles and 44 abstracts from five colleges on the University of Guelph campus. This is a great start, and it paves the way for even greater participation in future issues.

I encourage all undergraduates to consider submitting their work to SURG and taking part in editorial roles. You are the next generation of researchers, and your contributions are invaluable.

Sincerely,

Matt Teeter

SURG Editor 